\title{
Izrekanje resnice $v$ Ogledalu preprostih izničenih duš Margarete Porete
}

\author{
Iva Jevtić*
}

\section{UVOD}

Kadar omenim, da je osrednja tema mojega raziskovanja ženska srednjeveška mistika, se pri laiku največkrat porodi naslednja asociacija: »Torej ... čarovnice?« Povezava je na mestu, če nanjo pogledamo skozi prizmo nekropolitike, pojma, s katerim Achille Mbembe problematizira biopolitiko sodobnega časa in ga definira kot »skrajni izraz suverenosti [ki] večinoma leži v moči in zmožnosti, da določa, kdo naj živi in kdo umre«. ${ }^{1}$ Luč na koncu tunela heterodoksije je bila v srednjem veku lahko tudi grmada, fizično izničenje heretika ali njegovega dela, telesa in knjige. Margareta Porete in njeno delo, Ogledalo preprostih izničenih duš, sta bila tako deležna istega ognja.

Ogledalo preprostih izničenih duš je nastalo v začetku 14. stoletja v kontekstu gibanja begin, torej v okviru posvetne nabožnosti, ki je bila

* Univerza v Mariboru, Fakulteta za organizacijske vede, Kidričeva 55A, Kranj; iva_jevtic@yahoo.com.

1 Mbembe, Necropolitics, 66. Pojem nekropolitike se navdihuje pri Foucaultovi ideji biopolitike, ki premišljuje režime moči in vedenja ter procese subjektivacije, še posebno tiste, ki se nanašajo na temeljne življenjske procese. Biopolitika je po naravi "pozitivna«, kar pomeni, da deluje sočasno z negativnimi, represivnimi mehanizmi moči, ki življenje odvzamejo ali dopustijo, s tem da življenje podpira ali pa ga zavira. Tudi Mbembe pojem smrti razširi, tako da poleg svoje skrajne fizične oblike vključuje tudi različne oblike družbene smrti, "nove in izvirne oblike družbene eksistence, ki množice ljudi podredi življenjskim pogojem, ki jim podelijo status živih mrtvih« (ibid., 92). 
$\mathrm{s}$ stališča srednjeveške Cerkve vedno prežeta $\mathrm{z}$ implicitno nevarnostjo nepravovernosti. V Margaretinem primeru je ta strah dosegel vrhunec leta 1310, ko so jo v Parizu na zloglasnem morišču Place de Grève sežgali kot krivoverko. Porete ni ustvarjala pod okriljem uradne hierarhije, svoje duhovne avtoritete prav tako ni črpala iz videnj ali iz posebne vrste telesne duhovne izkušnje - vse to naj bi bile namreč značilnosti ženske srednjeveške nabožnosti. ${ }^{2}$ Ogledalo, ki je veljalo za izgubljeno do leta 1946, ko je ta rokopis Margareti Porete prepričljivo pripisala italijanska zgodovinarka Romana Guarnieri, ${ }^{3}$ se namreč napaja pri različnih virih in je žanrska mešanica srednjeveških romanc, truverske lirike, svetopisemskih prilik ter nabožne literature, ki jih predela $\mathrm{v}$ izvirno duhovno celoto. ${ }^{4}$

Margaretino besedilo je nastalo v tradiciji »zrcalne« literature, kjer je bilo ogledalo platonska prispodoba za samospoznanje in je imelo jasno izraženo mistagoško funkcijo. $\mathrm{Z}$ neprikrito avtoriteto premišljeno nagovarja raznovrstno bralstvo, $\mathrm{z}$ izjemo pripisa, o katerem več pozneje, pa se nikjer ne obrača na zunanjo avtoriteto, niti na pisarja, ki bi s svojo "nevidno " prisotnostjo besedilo navdal s potrebno veljavo ${ }^{6}$ Margareta je torej delo najverjetneje napisala sama - oziroma je imela dovolj sredstev, da je dala knjigo napisati. Vse to kaže, da je bila najbrž iz višjih krogov ali da je imela zaslombo pri vplivnem pokrovitelju, morda oboje. Tega žal ni mogoče vedeti, saj so edini zapisi o njenem življenju ohranjeni $\mathrm{v}$ inkvizitorskih dokumentih $\mathrm{z}$ njenega procesa in so temu primerno skopi oziroma specifični.

Kljub Margaretini sodbi se je Ogledalo ohranilo v številnih latinskih in srednjeangleških prepisih in je bilo priljubljena stalnica srednjeveške nabožne literature. Identifikacija njegove avtorice je bila plodovita podlaga za naraščajoče akademsko zanimanje za okoliščine

Ena najbolj prodornih študij družbenih ter političnih aspektov povezave med spolom in mistiko ostaja delo Grace Jantzen, Power, Gender, and Christian Mysticism. Specifiko telesne nabožnosti (tako ženske kot nasploh) obravnava Caroline Walker Bynum, denimo v delih Holy Feast and Holy Fast (o pomenu hrane oziroma "sveti anoreksiji kot matere); in Fragmentation and Redemption (o vprašanjih metodologije pri študijah povezav med spolom in nabožnostjo).

3 Guarnieri, »Lo Specchio delle anime semplici«, 661-663.

4 Kocher, »Literary Sources of the Mirror of Simple Souls«, 96-119.

5 De Gier, »The Role of the Mirror of Simple Souls as a Book«, 137.

6 Newman, »Annihilation and Authorship«, 615. O vzpostavljanju avtoritete v besedilih dveh srednjeangleških mistikinj piše Staley Johnson, "The Trope of the Scribe«. 
njegovega nastanka in vsebino, v zadnjih letih tudi v slovenščini.? Dosedanje obravnave Margaretinega dela so se pogosto dotikale vprašanja teološke heterodoksnosti Ogledala, feministične študije pa so Porete, tudi zaradi asociacije $z$ beginami, pogosto obravnavale kot protofeministko. ${ }^{8}$ Seveda sta tako vprašanji heterodoksije kot spola zgodovinsko pogojeni - v primeru morebitne heterodoksije je najboljši primer za to ravno Ogledalo, saj njegove izvlečke najdemo v verskih kompilacijah, ki so jih v poznem srednjem veku kot vodilo v duhovno življenje uporabljali tako kleriki kot laiki. ${ }^{9}$ Kljub temu, da je v času Margaretinega procesa kar 21 teologov presodilo, da Ogledalo ni v skladu s cerkvenim naukom, so ga poznejši bralci očitno šteli za dovolj neproblematično, da so ga lahko brali tudi novici ter celo posvetno bralstvo brez poglobljene teološke izobrazbe.

Pri vprašanju spola se kaže spomniti, da ženska v srednjeveškem svetu ustvarja v risu izjave svetega Pavla: Mulieres in ecclesiis taceant. ${ }^{10}$ Zgodovina Cerkve nedvomno pozna primere mistikinj, ki so bile relativno opolnomočene, sicer redko brez nasprotovanja, pa vendar - na misel prideta Katarina Sienska ali Tereza Avilska, katerih duhovni vpliv je pogosto dobil tudi politični domet. Vseeno pa se je lahko v luči Pavlove prepovedi ženska govorica, še posebno taka, ki je stala sama zase, vedno razprla v vsaj dve možnosti. Ženska, ki govori, pa ne bi smela, ni ženska, ni "prava« ženska - je pseudo-mulier, kot je

7 Delen prevod Ogledala je v sklopu knjige Božje trubadurke (Ljubljana: KUD Logos, 2018) dostopen v prevodu Milice Kač. Margaretino delo v nedavni doktorski disertaciji z naslovom »Med neizrekljivostjo in telesom «s psihoanalitskega in feminističnega vidika obravnava Tamara Podlesnik; v članku "Marguerite Porete in njeno Ogledalo preprostih duš« pa leta 2005 tudi Urška Čeferin.

8 Scarborough, „Critical Approaches to Marguerite Porete«, 319.

9 Juilfs, »Mirrors on the Wall«, 325, še posebej op. 11.

10 Tu se naslanjam na tradicionalno, splošno uveljavljeno interpretacijo Pavlovih besed iz Pisma Korinčanom (1 Kor 14,34). Vseeno opozarjam na zanimivo študijo, ki meni, da je Pavel trdil ravno nasprotno, $\mathrm{z}$ uporabo retorične figure citiranja in zavrnitve citiranega (quotation-refutation device), kar naj bi bilo razvidno iz odlomka 1 Kor 14,36, ki naj bi se nanašal specifično na moške: »Or did the word of God originate with you men, or to you men only has it come?' This twofold rhetorical question provides the key to unlocking the remainder of the passage, for it indicates in no uncertain terms that Paul disagrees sharply with the preceding thought unit or paragraph. The contrast between the women addressed in v. 34 - seen in the feminine plural 'they' (autais) - and the 'you men only' censured in v. 36 for their position in 14:33b-35, further demonstrates that 14:36-38 stands as a condemnation of $14: 33 b-35$ and the Corinthian men who proposed it.« MacGregor, »1 Corinthians 14:33b-38«, 25. 
Margareto označil inkvizitor; po drugi strani pa govorico, ki se izreka kljub prepovedi, avtorizira višja instanca - avtoriteta, ki jo prepoveduje, torej ni "prava« avtoriteta. Nastopi razkorak, ki postavlja pod vprašaj tako naravo avtoritete kot tudi tistega, ki jo naslavlja, ter vzpostavi nasprotje sil, ki so v veliki meri zaznamovale tudi okoliščine, kakršne so vodile do Margaretine obsodbe.

\section{ŠTIRJE NAČINI IZREKANJA RESNICE: OD PAREZIJE DO MODROSTI}

V nizu predavanj iz osemdesetih let o ideji parezije Michel Foucault izpostavi ravno ta trenutek ambivalence: kdo je tisti, ki lahko izreka resnico in pod kakšnimi pogoji? Parezija izvorno opisuje »odkriti govor «; parezijast je nekdo, ki govori resnico. ${ }^{11}$ Foucault na podlagi antičnih spisov opredeli štiri značilnosti svobodne govorice. To so iskrenost - govorec neposredno govori tisto, kar misli; resnica - govorčevo prepričanje in resnica sovpadata, ni dvoma, da je to, kar govori, res, res pa je zato, ker ve, da je res, oziroma ker je dokaz za to govorčev pogum; govorec se namreč vedno izreka v kontekstu nevarnosti - parezija je kritična govorica, ki naslavlja neke vrste avtoriteto, recimo tirana ali avtoriteto javnega mnenja, je kritična govorica, ki lahko govorcu škoduje; med značilnosti torej sodita tudi že omenjena kritičnost ter občutek dolžnosti (parezijast bi lahko molčal, vendar vseeno govori).

Kljub temu da Margaretin položaj na prvi pogled izpolnjuje vse kategorije »odkritega govora«, se zatakne ravno pri vprašanju spola. Parezija namreč ni prosto dostopna: da bi lahko človek svobodno govoril, sodeloval v igri »odkritega govora «, mora biti državljan in moški, sužnji in ženske so iz tovrstne izmenjave izključeni. ${ }^{12}$ Parezijast se mora zavedati svojega izvora, svojega statusa. Pravzaprav je ta predpogoj za resnično odkriti govor, drugače nastopi kriza parezije, kjer je mogoče reči karkoli in kjer to lahko reče vsakdo, »celo tujci in sužnji« ${ }^{13}$ Demokracija, na primer, kjer je vsakdo enak pred zakonom, je »obsojena na to, da zagotovi enak prostor vsem oblikam parezije, tudi najslabšim «, ${ }^{14}$

Foucault, Neustrašni govor, 3 .

Foucault je v odgovoru na vprašanje študenta, zakaj v svojih predavanjih vseskozi uporablja moški zaimek, »nakazal, da je ženskam njihova podrejena vloga v grški družbi na splošno onemogočala rabo parezije (kakor tudi tujcem, sužnjem in otrokom)«. Foucault, Neustrašni govor, 4, op. 3.

Ibid., 70, op. 51.

Ibid., 67. 
takšnim torej, ki se prilizujejo demosu in ki so namenjene osebni koristi in ne skupnemu dobru mesta. Od četrtega stoletja pr. Kr. dalje se tako o pareziji, vsaj v žlahtnem pomenu besede, bolj kot o institucionalni pravici vedno bolj premišljuje kot o osebni, etični drži.

Foucault razširi koncept parezije s tem, da ga identificira kot enega izmed štirih osnovnih načinov izrekanja resnice ("veridikcije«) v antičnem svetu; ostali trije so še preroštvo, modrost ter poučevanje. Vsak se povezuje z različnimi udeleženci, zahteva specifične načine govora in se nanaša na raznovrstne sfere (usodo, bit, tekhne in ethos). ${ }^{15}$ Vendar pa Foucault poudari, da ob tem ne gre za štiri zgodovinsko ločene družbene vloge - preroka, modreca, učitelja in parezijasta - temveč predvsem za različne načine veridikcije, ki se v različnih obdobjih povezujejo z različnim institucijami, praksami in ljudmi. In če jih $\mathrm{v}$ antičnem svetu lahko opazujemo še v relativno ločenih sferah, je zanje pozneje značilna ravno hibridnost, mešanje ter prehajanje iz enega modusa $v$ drugega.

$\mathrm{V}$ srednjeveškem svetu se, recimo, prepletajo $\mathrm{v}$ dveh specifičnih zgodovinskih pojavih, pridigarstvu in univerzi. Frančiškani in dominikanci so tako v svojih pridigah združevali preroštvo (prerok po definiciji ne govori v svojem, temveč v božjem imenu, njegove besede pa se nanašajo na prihodnost, $v$ tem primeru na sodni dan $)^{16}$ in parezijo (ljudem so brez strahu ter odkrito govorili o njihovih napakah). Univerza na drugi strani združuje modusa modrosti (izrekanja o naravi stvari) ter poučevanja (s strani nekoga, ki je dolžan posredovati svoje znanje in $\mathrm{z}$ drugimi vzpostaviti vez skupnega védenja in izročila). ${ }^{17}$

Če se na tej točki vrnemo k Margareti Porete, lahko ugotovimo, da prostora za izrekanje (svoje) resnice ni mogla najti v nobenem izmed zgoraj opisanih srednjeveških institucionalnih razmerij. Najprej, kot rečeno, ker je bila ženska. Ker je ustvarjala zunaj uradnih institucionalnih okvirjev ženske nabožnosti in tudi onkraj ustaljenih žanrskih konvencij duhovne literature, pa so ji bile nedostopne tudi alternativne možnosti legitimacije svojega življenja in dela. Kot je izpostavila Grace Jantzen, gre v primeru mistikinj pri njihovi mistiki obenem neizogibno tudi za projekt uveljavljanja svoje volje in vizije. Vsaka zase 
znotraj tradicije in institucije, ki jo ohranja, izdolbe prostor izrekanja, pogosto ravno na relaciji med telesom in besedilom. ${ }^{18}$

Tudi Margareta Porete je s svojo govorico, hote ali nehote, sodeč po samozavestnem tonu besedila in trudu, s katerim se je borila za uveljavitev, bolj verjetno hote vzpostavljala, recimo temu, parainstitucijo izrekanja resnice. Njena govorica je vključevala tako pisanje kot molk oziroma specifičen preplet prisotnosti (skozi medij knjige) in odsotnosti (skozi telesno razsežnost molka). Kako govori nekdo, že vnaprej izključen iz okvirjev, ki zarisujejo možnosti izrekanja resnice, nekdo, ki je brez statusa, ki bi ga vzpostavil kot možnega nosilca resnice ${ }^{? 9}$ Gre v takem primeru sploh za govorico? V kontekstu Margaretinega dela in življenja je o teh vprašanjih mogoče razmišljati v kontekstu vseh treh zgoraj omenjenih elementov veridikcije: njenih udeležencev, njenega predmeta ter načina govorice.

\section{SIVE EKONOMIJE ODREŠITVE}

Margareto so cerkvene oblasti leta 1310 obsodile zaradi herezije in jo predale posvetnim oblastem. Nato je bila 1. junija v Parizu sežgana, bojda hkrati s spreobrnjenim Judom, ki je bil obsojen zato, ker naj bi pljunil na podobo Device Marije. Sopostavitev je imela nedvomno tako politične kot povsem ikonografske in simbolne dimenzije. Po eni strani je zadovoljila politične apetite posvetnih oblasti, ki so zaradi sočasnega in izrazito kontroverznega pregona templjarjev s strani kralja Filipa IV. potrebovale enoznačno in javnosti všečno obsodbo. ${ }^{20}$ Po drugi strani in pogosto humorni mistični govorici se je v svojem delu Margery Kempe and Translations of the Flesh celovito posvetila Karma Lochrie, ki pokaže, da je nepismena Margery vešče redefinirala uveljavljene predstave o grešnosti in telesnosti. Tudi Margery se je hkrati strastno posvetila realizaciji svoje knjige, ki je - kot pri Margareti - prav tako žanrsko raznolika, nekje med hagiografijo in morda celo prvo (avto)biografijo $\mathrm{v}$ angleškem jeziku. V slovenščini je Knjiga Margery Kempe dostopna v prevodu Nike Kocijančič, ki je prispevala tudi uvodno študijo. Po mnenju Seana L. Fielda tedanja politična klima razloži ostrino sodbe tudi v Margaretinem primeru, ki je bil svojevrstna uvertura v pregon templjarjev in konsolidacijo podobe Filipa kot varuha ortodoksije. V članku »The Inquisitor Ralph of Ligny, Two German Templars, and Marguerite Porete« avtor postavi hipotezo, da je inkvizitor Rudolf iz Lignyja, ki je prvi izprašal Margareto o njeni domnevni kršitvi zapovedi, naj preneha s širjenjem svojega besedila, v približno istem obdobju izprašal tudi dva viteza templjarja in o tem v pismu poro- 
je vzpostavila simbolno povezavo med nepopravljivim Judom, ki se je kljub spreobrnitvi pregrešil zoper Marijino podobo, in nepopravljivo heretičarko Margareto, ki je kljub prepovedi še naprej širila svoj nauk in se ni zaradi tega nikoli pokesala, številnim priložnostim navkljub. ${ }^{21}$ Interesi posvetne oblasti so s cerkvenimi nesrečno sovpadli ravno $\mathrm{v}$ času, ko se je okrepil pregon posvetnih duhovnih gibanj. V kronikah Margaretinega procesa je ta opisana kot pseudo-mulier, psevdoženska oziroma neprava ženska, ter kot begina iz Hainuta. Pseudo-mulier sicer ni bila izvirna oznaka, saj so izraz sodobne kronike uporabile tudi v primerih drugih žensk, ki so prekršile zakon, vedno pa v kontekstu dvomljive duhovnosti, enkrat na primer za begino, drugič pa $v$ primeru morilske devineresse, vedeževalke. ${ }^{22}$ Vloga kršitelja postave in še posebno kršiteljice postave je bila torej v veliki meri tipizirana, sodbe pa so se v veliki meri zanašale na nabor simbolnih oznak, blasfemijo (recimo pri Poretinem sotrpinu, spreobrnjenem Judu), sodomijo, čarovništvo. ${ }^{23}$

To do neke mere postavi pod vprašaj Margaretin drugi opis, namreč to, da je bila begina. ${ }^{24}$ Glede na skopost zanesljivih podatkov o njenem življenju to ni izključeno: tako njen geografski izvor kot značilnosti njenega dela pričajo vsaj o izrazitem vplivu, če ne celo o pripadnosti gibanju. Po drugi strani pa je bila morda označena za begino podobno, kot so Margery Kempe označili za lolardko, torej bolj v risu cerkvenih strahov pred posvetnimi duhovnimi gibanji, ne nujno na podlagi dejstev. Vprašanje, ali je bila Margarete tudi dejansko begina, tukajšnjega razmisleka ne spremeni bistveno, saj je v krogotoku juridičnih asociacij dejstvo, da Margareto Porete opišejo kot begino, le okrajšava za to, da je pseudo-mulier, da je nepopravljiva heretičarka, da je kriva.

Pravzaprav je bil celoten odnos cerkvenih oblasti do "gibanja svobodnega duha" precej fantazmatski, saj so si ga morale, zato

čal Filipu. Prim. Field, „Debating the Historical Marguerite Porete«, 9-37. Na preplet posvetnih in cerkvenih interesov kaže tudi dejstvo, da je bil dominikanec Viljem iz Pariza, inkvizitor, ki je vodil Margaretin proces, obenem tudi Filipov spovednik; Field, The Beguine, the Angel, and the Inquisitor, 18.

O inherentni srednjeveški sumničavosti do spreobrnjenih Judov, ki so kljub spreobrnitvi zaradi svoje nepopravljive narave nezmožni prave spremembe, piše Kruger, Spectral Jew, 168. Field, The Beguine, the Angel, and the Inquisitor, 17-18. Field, ibid., meni, da je primer Margarete Porete poseben ravno zato, ker teh oznak večinoma ni.

24 Field, The Beguine, the Angel, and the Inquisitor, 30-31. Glej tudi Field, »Debating the Historical Marguerite Porete«, 24-25. 
da bi lahko preganjale, najprej v veliki meri tudi namisliti - torej poenotiti raznorodne struje $\mathrm{v}$ enovito gibanje $\mathrm{z}$ jasno definiranimi značilnostmi. ${ }^{25} \mathrm{Ob}$ tem jih je nedvomno motilo, da so begine kljub umeščenosti v posvetno življenje živele duhovno življenje, bodisi v skupnostih, beginažah, bodisi kot popotne učiteljice. Pogosto so tako poučevale kot pridigale in tako živele zunaj pripoznanih definicij ženskosti, ${ }^{26}$ obenem pa tudi izven okvirjev, ki bi lahko do neke mere omilili njihovo transgresijo uveljavljenih družbeno-spolnih norm. K razvoju gibanja je prispevalo več faktorjev, med drugim finančno težko dosegljiv vstop v samostan, ${ }^{27}$ pa tudi splošen razvoj laičnih žensk, ki se je iz patristične tradicije in pozneje s posredovanjem Tomaža Akvinskega prenesla tudi v srednjeveške kanone (Tomaž Akvinski sicer sklene, da ženske lahko učijo, a le v sferi zasebnega pogovora; glej Blamires, »Woman Not to Preach: A Disputation in British Library Ms Harley 31«, 41). Kljub redkim izjemam, denimo že omenjeni Katarini Sienski, kjer je morebiti »čistost življenja omilila šibkost spola«, so bile tiste redke ženske, ki so se uspešno javno izrekale, razumljene kot točno to, izjeme, ki se jih v nobenem primeru ni smelo posnemati (»veneranda non imitanda«), saj niso bile normalne ženske: »[N]ormal women, be they lay or religious, should not aspire to the role of preacher or teacher of matters petaining to faith or doctrine. « Roest, "Female Preaching in the Late Medieval Franciscan Tradition«, 129 -130.

27 Gibanje begin je šlo skozi različne stopnje razvoja, najprej je šlo zgolj za nepovezane posameznice, "svete ženske« (mulieres sanctae), povsem spontano gibanje, ki se je do neke mere formaliziralo šele, ko so se začele združevati v skupnosti. Tu, pravi Elizabeth Petroff, se je vmešala Cerkev, saj je želela, da bi bile te pod okriljem že uveljavljenih redov. A teh, dodaja, niso zanimale revne ženske brez dot, »the existing orders were not interested in taking in more women, especially poor women without dowries, and they made no allowance for women who supported themselves by working." Petroff, Body and Soul: Essays on Medieval Women, and Mysticism, 54. Izraz dota se tu nanaša na »duhovno doto«: te so bile sicer v teoriji prepovedane, v praksi pa dokaj uveljavljen predpogoj za vstop v samostan (glej Power, Medieval English Nunneries c.1275-1535, 16). Vsota, ki so jo morale ženske plačati ob vstopu, je bila običajno res nižja kot običajna dota: tudi zato so bili samostani pogosto »odlagališče« (ali pa zatočišče, odvisno od perspektive) neporočenih žensk iz aristokracije, ki so si vstop zagotovile $\mathrm{z}$ bogastvom in/ali umeščenostjo v sistem pokroviteljstva, s katerim so bogate družine ženskim samostanom zagotavljale nujno potrebno ekonomsko osnovo. (O tesnem odnosu med družinami pokroviteljev in ženskimi samostani več v Röckelein, "Founders, Donors, and Saints: Patrons of Nuns' Convents«, še posebno 222-223, ki se nanaša ravno na ekonomske zagate ženskih samostanov v 13. stoletju.) Za razliko od moških samostanov so bili namreč ženski samostani bolj strogo podvrženi klavzuri (še posebno po papeški buli o nunski klavzuri 
gibanj, ki so v zgledu apostolskega življenja in zmesi aktivnega in kontemplativnega življenja videla možnost za bivanje onkraj cerkvenih in tudi ekonomskih omejitev.

Z bulo Ad nostrum je leta 1311 Cerkev dokončno obsodila begarde in begine in jih spoznala kot pripadnike herezije svobodnega duha. Kot heretična to besedilo med drugim navaja naslednja prepričanja:

Primo videlicet, quod homo in vita praesenti tantum et talem perfectionis gradum potest acquirere, quod reddetur penitus impeccabilis, et amplius in gratia proficere non valebit. Nam, ut dicunt, si quis semper posset proficere, posset aliquis Christo perfectior inveniri. Secundo, quod ieiunare non oportet hominem, nec orare, postquam gradum perfectionis huiusmodi fuerit assecutus, quia tunc sensualitas est ita perfecte spiritui et ratione subiecta, quod homo potest libere corpori concedere quicquid placet. Tertio, quod illi, qui sunt in praedicto gradu perfectionis et spiritu libertatis, non sunt humanae subiecti obedientiae, nec ad aliqua praecepta ecclesiae obligantur, quia, ut asserunt, ubi spiritus Domini, ibi libertas. Quarto, quod homo potest ita finalem beatitudinem secundum omnem gradum perfectionis in praesenti assequi, sicut eam in vita obtinebit beata. Quinto, quod quaelibet intellectualis natura in se ipsa naturaliter est beata, quodque anima non indiget lumine gloriae, ipsam elevante ad Deum videndum, et eo beate fruendum. Sexto, quod se in actibus exercere virtutum est hominis imperfecti, et perfecta anima licentiat a se virtutes. Septimo, quod mulieris osculum (quum ad hoc natura non inclinet) est mortale peccatum, actus autem carnalis, quum ad hoc natura inclinet, peccatum non est, maxime quum tentatur exercens.

Prvič, da lahko človek že v tem življenju doseže takšno in tolikšno stopnjo popolnosti, da postane popolnoma nezmožen greha in ne more več napredovati v [božji] milosti. Trdijo namreč, da bi, ko

Periculoso Bonifacija viII. iz leta 1298) in si zato pogosto niso mogli zagotoviti preživetja z ekonomskimi dejavnostmi (gl. Rösener, "Household and Prayer: Medieval Convents as Economic Entities«, 245) ali beračenjem. To se je odražalo tudi v strukturi srednjeveških samostanov, v katerem so bile večinoma pripadnice aristokracije in višjih razredov, ki so sčasoma vključevali tudi ženske iz bogatih trgovskih družin, še posebno v samostanih blizu mest (Medieval English Nunneries, 10-12). Beginaže so bile bolj družbeno heterogene (Mizruchi, Regulating Society: Beguines, Bohemians, and Other Marginals, 55), begine pa so si lahko zagotovile ekonomsko neodvisnost $\mathrm{z}$ različnimi deli, denimo z vezenjem, šivanjem, celo $\mathrm{z}$ varjenjem piva ali s prepisovanjem rokopisov (Rösener, »Household and Prayer: Medieval Convents as Economic Entities«, 256). 
bi lahko vedno napredoval, kak človek lahko postal popolnejši od Kristusa. Drugič, da ko človek doseže takšno stopnjo popolnosti, ni več treba, da bi se postil ali molil, saj so njegovi čuti tako docela podvrženi duhu in razumu, da svojemu telesu lahko prosto dovoli vse, kar si želi. Tretjič, da tisti, ki so v omenjenem stanju popolnosti in duhu svobode, niso več podvrženi človeški poslušnosti ali kakim cerkvenim naukom, kajti, kot trdijo, je tam, kjer je Gospodov duh, tudi svoboda. Četrtič, da človek lahko tako že v tem življenju doseže skrajno blaženost v skladu z vsako stopnjo popolnosti, ki mu bo sicer dana v blaženem življenju. Petič, da je sleherna umna narava že sama v sebi po naravi blažena in da duša ne potrebuje svetlobe slave, s katero bi se povzdignila k zrenju Boga in užila njegovo blaženost. Šestič, da je udejanjanje kreposti znak človekove nepopolnosti in da je popolna duša prosta kreposti. Sedmič, da je poljub ženske (ker k temu narava ne nagovarja) smrtni greh, meseno dejanje, ki je posledica naravnega vzgiba, pa ni greh, še posebno, če je posledica skušnjave. ${ }^{28}$

Margareto so obsodili na podlagi odlomkov, ki so v marsičem podobni, celo istovetni, heretičnim prestopkom, popisanim v buli, ki je nastala nedolgo po njeni smrti in po prepričanju številnih zgodovinarjev tudi na podlagi njenega dela. Četudi Margareta govori o zapuščanju kreposti, si lahko duša, ki je do te mere izničena, da je eno z Bogom, lahko želi le to, kar si želi Bog. Vse stopnje združenja z Bogom (ki jih je sedem) so odvisne od božje milosti, ki jih vodi. Je torej spodnji Margaretin opis tega, kako se poslavlja od kreposti, res heretičen?

Vertuz, je prens congé de vous a tousjours,

Je en auray le cueur plus franc et plus gay;

Voustre service est troup coustant, bien le sçay.

Je mis ung temps mon cueur en vous, sans nulle dessevree;

Vous savez que je estoie a vous trestoute habandonnee;

Je estoie adonc serve de vous, or en suis delivree.

J'avoie en vous tout mon cueur mis, bien le sçay,

Dont je vescu ung tandis en grant esmay.

Souffert en ay maint gref tourment, mainte paine enduree;

Merveilles est quant nullement en suis vive eschappee;

Mais puis que ainsi est, ne me chault: je suis de vous sevree,

Dont je mercie le Dieu d'en hault; bonne m'est la journee.

28 Conciliorum oecumenicorum decreta, ur. Alberigo et al., 359-36o. Kjer ni navedeno drugače, so prevodi avtoričini. 
De voz dangers partie sui, ou je esté en maint ennui.

Oncques mais franche ne fui, fors de vous dessevree;

Partie suis de voz dangers, en paix suis demouree.

Kreposti, za vedno se poslavljam od vas, srečnejše in svobodnejše bo moje srce.

Dobro vem, kako zvezana sem v vaši službi,

saj sem vam nekdaj povsem podarila srce.

Veste, Kreposti, kako sem se vam povsem prepustila.

Bila sem vaša sužnja, sedaj pa sem prosta.

V celoti sem vam dala srce, o tem ni dvoma, in dolgo živela v velikih težavah.

Pestile so me mnoge muke, prestala sem mnogo bolečin.

Pravi čudež je, da sem se rešila živa,

in ker sem se rešila živa, mi vsega tega ni več mar,

ločena sem od vas.

Za to sem hvaležna Bogu na višavah:

zame je prazničen dan.

Zapustila sem vaše nevarnosti,

ki so rojevale tolike bolečine.

Nikoli nisem bila svobodna,

dokler se nisem ločila od vas.

Zapustila sem vaše nevarnosti in sedaj živim v miru. ${ }^{29}$

V luči zgoraj opisanih alternativnih odrešenjskih ekonomij morda ni nenavadno, da so cerkvene oblasti Margaretino Ogledalo brale selektivno. Margareta je bila obsojena kot pseudo-mulier, vendar ta priročna okrajšava, ki problematizira Margaretin spol, obenem zakrije druge problematične vidike njenega dela. Ti ne

Poglavje 6, citirano po izdaji Romane Guarnieri in Paula Verdeyena, Marguerite Porete: Speculum simplicium animarum / Le mirouer des simples âmes, Corpus Christianorum continuatio mediaevalis 69 (Turnhout: Brepols, 1986), 24, zgoraj nastopa v srednjefrancoskem izvirniku, ker latinski tekst na tem mestu ni popoln: „Virtutes, a vobis nunc pro semper recedo. / Et ideo cor meum magis erit liberum et ampliore pace fruetur. / Servire vobis nimis <costat $>$, bene scio. / Aliquo tempore posui cor meum in vobis inseparabiliter. / Hoc scitis: tota eram vobis dedita. / Ideo tunc eram vestra sclava, sed modo sum expedita. ... Multas amaritudines et dura tormenta sustinui in vestro servitio. / Et miror quomodo sic evasi. ... Numquam profecto fui libera, donec a vobis fui separata.«V slovenskem prevodu Milice Kač, Epiney-Burgard in Zum Brunn, Božje trubadurke, 202. 
kršijo zgolj cerkvene postave, temveč tudi posvetno, ki je bila $\mathrm{v}$ srednjem veku s prvo tesno prepletena. Kot begina, prava ali namišljena, Margareta Porete izstopi iz ekonomije spola; kot pripadnica gibanja, ki je, vsaj deklarativno, prakticiralo uboštvo, ${ }^{30}$ je izstopila iz ekonomije dela; z zapuščanjem kreposti je izstopila iz ekonomije greha. Verskim in posvetnim oblastem je Margareta izrekala resnico osvobojenega in odrešenega telesa, ki si tukaj in zdaj "prosto dovoli vse, kar si želi«.

\section{(NE)VIDNA ROKA TRGA POKORE}

Raoul Vaneigem v svoji knjigi Gibanje svobodnega duha zapiše: „Cerkev je prezirala vsak greh, ki ni bil dobičkonosen. $\ll^{31} \mathrm{Trg}$ pokore, kot ga imenuje, se dobro znajde s pogoltneži, morilci in pijanci, ne ve pa, kaj bi z asketi, ki so brez želje, s poštenimi ljudmi ali, kot v primeru gibanja "svobodnega duha", $\mathrm{z}$ ljudmi, ki verjamejo v prvobitno nedolžnost narave. Kaj storiti z nekom kot Margareta, ki ne želi ničesar ali, povedano drugače, hoče nič? S takimi, ki ukinjajo posredniško vlogo Cerkve, ni mogoče trgovati.

David Kangas prepozna v ideji »kreposti« stik med političnim in teološkim; »kreposti« so družbeno predpisan nabor normativnih praks, ekonomija kreposti pa vzpostavlja vrednost v obliki zasluge. Normativnost zasluge temelji na prepričanju o »končnem cilju« človeškega življenja. ${ }^{32} \mathrm{~V}$ nasprotju s tem pri Margareti Porete človeško življenje ne pozna nikakršnega zakaj. Margareta trdi, da Cerkev svobodne duše ne razume:

30 O revolucionarnih, odrešitvenih in karnevalskih aspektih gibanja v svojem po lastnih besedah eksplicitno neakademskem delu spregovori Raoul Vaneigem: »In its radical conception - when it does not demand humiliation - the practice of voluntary poverty challenges having, as impeding the freedom of being. The money that was solicited, panhandled, found or stolen by the community in Cologne was neither saved nor used as capital: it was used to binge on food and drink, "sent into eternity," accompanied, if necessary, by its previous owner if he argued that it was still his. Beneath their cowls and rags, the Beguines of Schweidnitz wore delicate underclothes (confiscated from the novices). Concerned that their indulgence in luxury might be found offensive, the Loyists wore garments of rich silk made to look like work clothes (those of plasterers, roofers, fishmongers) «. Vaneigem, Movement of Free Spirit, 251.

31 Vaneigem, Movement of Free Spirit, 85.

32 Kangas, »Dangerous Joy: Marguerite Porete's Good-bye to the Virtues«, 301-303. 
Ipsa [anima] est ita longe ab opere virtutum, quod non potest earum intelligere linguagium. Sed opera virtutum sunt omnia inclusa infra talem animam, quae absque contradictione ei oboediunt. Et propter talem inclusionem nescit haec sancta ecclesia cognoscere. Quae sancta ecclesia singulariter laudat divinum timorem, quia sanctus timor Dei est unum donorum Spiritus sancti. Et nichilominus tamen destrueret timor Dei esse libertatis, si in tale esse posset intrare. Perfecta libertas non habet aliquod propter quid. [...] Plus seu maius expedivit eam a debitis quae Christo debebat, et ideo sibi nichil debet, quomodocumque fuerit obligata. Plus seu maius ostendit ei seipsum, quod eam expedivit de minori. Quod quidem plus seu maius vult habere sine omni intermedio intra eam plenum situm. Sed magnus sensus naturae quo decepti permittunt se regi per affectionem vitae spiritus in contentando seipsos de seipsis, aufert eis profundum, quod videlicet non possunt intelligere nuditatem huius profundi nec bonitatem Dei pro eis largiter credere. Et ideo permanent ipsi in operibus.

Sama [duša] je tako daleč od dejanj kreposti, da ne more razumeti njihovega jezika. Vendar so dela kreposti, ki brez ugovora ubogajo dušo, v taki duši v celoti zaobjeta. In zaradi tega sveta Cerkev ne ve, kako jih razumeti. Sveta Cerkev slavi bogaboječnost, saj je sveti strah božji eden izmed darov Svetega Duha. Vendar pa bi strah božji oropal bitje svobode, ko bi v tako bitje sploh lahko prodrl. Popolna svoboda ne pozna nobenega zakaj. [...] Nekaj več ali večjega jo je osvobodilo vseh dolgov, ki jih je bila dolžna Kristusu, zato mu ni dolžna nič, ne glede na to, kako veliko mu je dolgovala prej. Nekaj več ali večjega se ji pokaže, da jo osvobodi manjšega. To več ali večje jo želi posedovati v celoti, brez posrednika. Silni občutek narave, s katerim se zaslepljeni pustijo ravnati po hotenju življenja v duhu in se zato v sebi borijo proti sebi, pa uniči globino zaslepljenih, saj niso zmožni razumeti golote te globine niti ne verjeti v dobroto Boga, ki se jim naklanja. Zato ostanejo v svojih delih..$^{33}$

Namesto del ponuja Margareta nedelovanje, namesto hotenja nehotenje, namesto blaženosti bivanja $\mathrm{v}$ onostranstvu radost življenja tukaj. Kangas gre korak dalje in trdi, da Margareta v celoti zapusti tako občutek manka kot zadoščenje njegovega onostranskega polnila 
ravno s tem, ko »hoče nič«, ko pomanjkanje voljno pripozna in ga s tem obenem izniči: na ta način izstopi iz sistema kreposti. ${ }^{34}$

S tem seveda zanika tudi posredniško avtoriteto Cerkve; v Ogledalu vseskozi govori o »nižji sveti Cerkvi« in »višji sveti Cerkvi«, sestavljeni iz resnično osvobojenih duš, ki so tudi resnično plemenite duše, kot jim pravi Margareta. Če smo se prej vprašali, kako govori nekdo brez statusa, sedaj vidimo, da to počne s sklicevanjem na neko drugo genealogijo, $\mathrm{z}$ redefinicijo plemenitosti. ${ }^{35} \mathrm{Tu}$ je potrebno omeniti, da se Margareta ni želela prikazati pred inkvizitorji in da je ves čas procesa molčala, kljub temu, da so jo pozvali, naj prizna »resnico «; ${ }^{36}$ osemnajst mesecev je preživela $\mathrm{v}$ ječi in ker se $\mathrm{v}$ tem času ni pokesala, so jo na koncu obsodili kot nepopravljivo krivoverko. ${ }^{37}$ Moč inkvizicije namreč ni temeljila zgolj na represiji, temveč tudi na produkciji, predvsem na stvarjenju subjekta, ki ga Arnold poimenuje the confessing subject,,$^{38}$ izpovedujoči subjekt. Margareta se temu dosledno izogne z močjo molka in nedelovanja, ta pa nedvomno temelji tudi na dokončnem obratu v igri »svobodnega govora«, saj je zdaj osvobojena duša tista, ki nastopa $v$ vlogi avtoritete in tudi tista, ki odloča, kdo lahko nastopa v vlogi tistega, ki izreka resnico. Margareta tako v Ogledalu zapiše:

Ipsa [anima libera] nulli respondet nisi velit, nisi sit de genere suo, quia nobilis homo non dignaretur uni rustico, si ipsum appellaret de campo. Et ideo non invenit talis anima qui ipsam appellet. Inimici numquam amplius habent $\mathrm{ab}$ ea responsum.

34 Kangas, "Dangerous Joy: Marguerite Porete's Good-bye to the Virtues«, 313.

35 Margareta Porete govori o dveh človeških rodovih, navadnem in plemenitem. Navadni je obsojen na dobra dela; plemeniti lahko doseže duhovni uvid z izničenjem. Pri tem se na plemenitost sklicuje, kot zapiše Robinson, izključujoče: "Here, as in numerous other places in her book, Porete invokes a lofty lineage to exclude those who cannot make a claim to it."Robinson, Nobility and Annihilation in Marguerite Porete's Mirror of Simple Souls, 90.

36 Zahteva po »celotni resnici« je bila sicer del inkvizitorskega protokola zaslišanj, ki ga v svojem priročniku Practica inquisitionis haereticae pravitatis opiše Bernard Gui; Verdeyen, „Le procès de l'Inquisition contre Marguerite Porete et Guiard de Cressonessart (1309-10)«, 63-64.

37 V kontekstu kulture mučeništva v poznem srednjem veku lahko Margaretin molk lahko razumemo tudi strateško; njena smrt je mnoge ganila »do solz«, kar je bil pogost motiv v opisih mučeniških smrti. Morda je toliko bolj nenavadno, da ga najdemo v opisu enega izmed 21 teologov, ki so Margareto obsodili na smrt; Rubin, »Choosing Death? Experiences of Martyrdom in Late Medieval Europe«, 173-174.

38 Kangas, »Dangerous Joy: Marguerite Porete’s Good-bye to the Virtues«, 318. 
Osvobojena duša nikomur ne odgovori, če noče, razen če ne govori s sebi enakim; ravno tako kot plemič ne odgovori kakemu kmetu, če ga ta ogovori s polja. Takšna duša ne zazna tega, ki jo ogovarja. Njeni sovražniki zato ne dobijo od nje nobenega odgovora. ${ }^{39}$

Margaretin molk pa ni zgolj posledica miselne ali duhovne redefinicije družbene moči. Povezan je tudi z naravo resnice, ki jo izreka, saj ta politizira čas odrešenja ravno $s$ tem, ko ga prestavi v sedanjost. Tako obenem zapusti tudi modus preroštva, ki je v osnovi naravnano na prihodnost, odreče se posredništvu, saj govori le zase, in "nikomur ne odgovarja, če noče«. Molči, ker hoče molčati. In po Foucaultu je prav to lastnost modreca, saj se ta ne čuti dolžnega izrekati resnico dovoljen mu je tudi umik. Margareta tako oblastem še enkrat prepusti zgolj telo, osvobojeno interpretacij.

\section{NEDOKONČANA RESNICA}

To ji v veliki meri omogoči njen alternativni medij izrekanja, njena knjiga, ki ima pri Margareti prav poseben pomen: $\mathrm{v}$ svojem besedilu jo omeni (kot ca livre) kar petinšestdesetkrat..$^{40}$ Verjetno ni naključje, da so, še preden so sežgali Margareto, sežgali njeno knjigo, nekje med letoma 1296 in 1306, in to v njeni prisotnosti. Tudi obtožnica zoper Margareto se dotika predvsem njene knjige:

Dicta Margarita librum quemdam composuerat continentem hereses et errores, qui de mandato reverendi patris domini Guidonis, condam Cameracensis episcopi, publice et sollempniter tamquam talis fuit condempnatus et combustus. Et per litteram predicti episcopi fuit ordinatum quod, si talia sicut ea que continebantur in libro, de cetero attemptaret verbo vel scripto, eam condempnabat et relinquebat iustitiandam iustitie seculari. Invenit etiam idem inquisitor quod ipsa recognivit in iudicio semel coram inquisitore Lotharingie et semel coram reverendo patre domino Philippo, tune Cameracensi episcopo, se post condempnationem predictam habuisse librum dictum et alios. Invenit etiam inquisitor quod dicta Margarita dictum librum in suo consimili eosdem continentem errores post ipsius libri condempna- 
tionem reverendo patri domino Johanni, Dei gratia Cathalaunensi episcopo, communicavit ac necdum dicto domino sed et pluribus aliis personis simplicibus, begardis et aliis, tamquam bonum.

Omenjena Margareta je napisala neko knjigo, ki je vsebovala herezije in napake in je bila kot taka javno ter svečano obsojena in zažgana na ukaz gospoda Guya, nekdanjega cambraiškega škofa. Omenjeni škof je pisno odredil, da jo bo v primeru, ko bi spet poskusila širiti $\mathrm{z}$ govorjeno ali pisano besedo takšne stvari, kakršne so vsebovane $\mathrm{v}$ knjigi, obsodil in jo predal posvetnim oblastem. Inkvizitor je ugotovil, kako je potrdila v procesu pred lotarinškim inkvizitorjem, pred častitim očetom gospodom Filipom, tedaj cambraiškim škofom, da ima še vedno, celo po omenjeni obsodbi, v lasti to in nekatere druge knjige. Inkvizitor je prav tako ugotovil, da je po obsodbi knjige to knjigo poslala častitemu očetu gospodu Janezu, po božji milosti škofu v Châlonsu, in ne samo temu gospodu, temveč tudi mnogim drugim preprostim osebam, begardom in drugim, kot bi bila brez napak. ${ }^{41}$

$\mathrm{V}$ razdelku "Approbatio«, ki ga sicer najdemo samo v latinskih in srednjeangleških kopijah Ogledala, Margareta sama pove, da je knjigo poslala v pregled omenjenemu Janezu, pa tudi cistercijanskemu menihu Dom Francu in uglednemu teologu Godfreyju iz Fontainesa. Vsi trije so knjigo označili za neproblematično, vendar je Godfrey opozoril, da jo smejo brati le redki, saj je prišla »od tako močnega in gorečega duha", da so mu le redki kos. ${ }^{42}$

Kako v luči nehotenja in v kontekstu omenjene osvobojenosti duše sploh razumeti Margaretin obrat k duhovnim avtoritetam in sklicevanjem nanje? ${ }^{23}$ Ali če zvedemo Margaretin »hoteti nič« do skrajnosti, kako sploh razložiti impulz za nastanek njene knjige? Zdi se, da se tudi Margareta zaveda paradoksnosti lastne pozicije, saj vsaj dve poglavji nameni nastanku besedila. Najprej zapiše, da je knjiga nastala na prigovarjanje Ljubezni:

41 Archives Nationales, J.428, 19 bis; citirano po Verdeyen, Le procès, 78.

42 Epiney-Burgard in Zum Brunn, Božje trubadurke, 192.

43 Field postavi hipotezo, da naj bi Porete iskala odobritev in podporo za svoje besedilo nekje med prvo obsodbo njene knjige leta 1306 in ponovnim procesom; Field, »Debating the Historical Marguerite Porete«, 27. 
Vos, sanctae ecclesiae pueri, dicit Amor, pro vobis feci hunc librum scribi, ut ad magnam vestram utilitatem audiatis vitae perfectionem et esse pacis, ad quod creatura pervenire potest per virtutem perfectae caritatis...

To knjigo sem naredila za vas, pravi Ljubezen, otročiči svete Cerkve, tako da lahko slišite in ste s tem bolj vredni izpopolnjenega življenja in obstoja v miru, ki ju lahko doseže bitje vsled popolne milosti ... ${ }^{44}$

Pozneje pa Margareta skozi nagovor Duše doda, da se zaveda nižje narave te knjige:

Nesciebam cui dicerem meum intentum. Nunc autem recognosco pro vestra pace et pro veritate rei, quod est de infimis. Formidolositas duxit eum [...]. Fuit etiam collatus per humanam scientiam et humanos sensus, sed humanus sensus nec humana ratio aliquid sciunt de interiori amore, nec amor interior aliquid de divina scientia. Cor meum ita ad sublimia tractatur et ita ad infima descendit, quod hoc non possum attingere.

Nisem vedela, komu naj govorim o svojih namenih. Zdaj pa ugotavljam, zaradi vašega miru in resnice, da prihaja ta knjiga od nižjih reči. Strahopetnost je narekovala to knjigo [...], ki jo je ustvarilo človeško vedenje in človeški čuti, toda človeško vedenje in človeški čuti ne vedo ničesar o notranji ljubezni, notranja ljubezen pa ničesar o božjem spoznanju. Moje srce je poletelo tako visoko in obenem padlo tako nizko, da ne morem do tega.$^{45}$

Tudi srednjeangleška mistikinja Julijana iz Norwicha ob koncu svoje knjige znamenito zapiše: »This boke ... is not yet performed. ${ }^{46}$ Eden izmed razlogov za tak nagovor je nedvomno to, da knjiga, še posebno srednjeveška knjiga, predvideva aktivno oziroma kontemplativno udeleženost bralca. ${ }^{47} \mathrm{~V}$ tem smislu je sedaj knjiga tista, ki postane medij izrekanja resnice. Po svoji naravi je preroško naravnana, vendar ne zato, ker bi posredovala končno resnico o človekovi usodi, temveč

Poglavje 2, СССм, 15 .

46 Julian of Norwich, The Writings of Julian of Norwich, poglavje 86.1, 379.

47 O središčni vlogi bralcev in branja in ideji "soudeleženega branja " pri pisanju besedil v poznem srednjem veku piše Blatt, Participatory Reading in Late-Medieval England. 
zaradi svoje temeljne usmerjenosti v prihodnost, $\mathrm{v}$ sodelovanje bralstva, ki jo edino lahko dopolni s svojo interpretacijo. Margareta molči, ker zanjo govori knjiga. Po drugi strani pa je ravno Margaretin pogumni molk pred oblastmi zagotovilo, da knjiga izreka resnico - da je od nižjega in višjega življenja hkrati.

Ogledalo je klasičen primer mističnega ekscesa; bolj ko je Bog neizrekljiv, več govori o njem. $V$ luči elementov izrekanja resnice pa je obenem tudi prostor porajanja govorice, forum radikalnosti, $\mathrm{v}$ katerem lahko na novo zaživijo preobrnjene genealogije, statusi in avtoritete. Kljub temu, da je knjigo nemogoče dokončati, je ravno knjiga tista, ki dopolni Margaretino delovanje - oziroma nedelovanje. Medij tako postane ključen element izrekanja resnice, nujen za celovito razumevanje vsakokratne situacije »odprtega govora«. Konec koncev je ravno s knjigo Margareti Porete uspel še zadnji in morda najbolj spektakularni obrat. Kot rečeno, je Margareta za Ogledalo plačala z življenjem. Sodeč po številnih ohranjenih prepisih pa je delo poželo navdušenje bralcev, saj so ga brali še stoletja po njegovem nastanku. Videti je, da je nevarnosti, ob kontinuiranem branju o možnostih osvobojene duše, navsezadnje podlegla tudi dogma. V luči Margaretinega življenja in smrti lahko Ogledalo preprostih izničenih duš razumemo kot ključen element njenega boja, da bi ustvarila prostor za izrekanje resnice, ki je tudi v tem smislu aktualen še danes. Razkriva zgodovinsko naravo silnic, ki tekste (in osebe) legitimirajo, avtorizirajo, podpirajo - ali zatirajo. 


\section{BIBLIOGRAFIJA}

\section{PRIMARNI VIRI}

Alberigo, Giuseppe, Perikles P. Joannou, Claudio Leonardi in Paolo Prodi, izd. Conciliorum oecumenicorum decreta. Freiburg im Breisgau: Herder, 1962.

Babinsky, Ellen, prev. in uvod. Marguerite Porete: The Mirror of Simple Souls. New York: Paulist Press, 1993.

Guarnieri, Romana, in Paul Verdeyen, ur. Marguerite Porete: Speculum simplicium animarum / Le mirouer des simples âmes. Corpus Christianorum - continuatio mediaevalis 69. Turnhout: Brepols, 1986.

\section{SEKUNDARNI VIRI}

Blamires, Alcuin. »Woman Not to Preach: A Disputation in British Library ms Harley 31.«The Journal of Medieval Latin 3 (1993): 34-63. Blatt, Heather. Participatory Reading in Late Medieval England. Manchester: Manchester University Press, 2018.

Bynum, Caroline Walker. Holy Feast and Holy Fast: The Religious Significance of Food to Medieval Women. Berkeley: University of California Press, 1987.

- Jesus as Mother: Studies in the Spirituality of the High Middle Ages. Publications of the Center for Medieval and Renaissance Studies, UCLA, 16. Berkeley: University of California Press, 1982.

- Fragmentation and Redemption: Essays on Gender and the Human Body in Medieval Religion. New York: Zone Books, 1991.

Čeferin, Urška. »Marguerite Porete in njeno Ogledalo«. Diplomsko delo. Univerza na Primorskem,2005.

—_. "Marguerite Porete in njeno Ogledalo preprostih duš.» Poligrafi 10.39/40 (2005): 203-225.

De Gier, Inke. "The Role of the Mirror of Simple Souls as a Book«. V: A Companion to Marguerite Porete and The Mirror of Simple Souls. Boston: Brill, 2017, 120-150.

Epiney-Burgard, Georgette, in Emilie Zum Brunn. Božje trubadurke: Mistikinje srednjega veka. Prevedla Milica Kač. Ljubljana: KUD Logos, 2018.

Field, Sean L. The Beguine, the Angel, and the Inquisitor: The Trial of Marguerite Porete and Guiard of Cressonessart. Notre Dame: University of Notre Dame Press, 2012. 
. "Debating the Historical Marguerite Porete«. V: A Companion to Marguerite Porete and The Mirror of Simple Souls, 9-37. Boston: Brill, 2017.

- . The Inquisitor Ralph of Ligny, Two German Templars, and Marguerite Porete«. Journal of Medieval Religious Cultures 39/1 (2013): 1-22.

Foucault, Michel. Neustrašni govor. Ljubljana: Sophia, 2009.

- The Courage of Truth: The Government of Self and Others II; Lectures at the College de France 1983-1984. Basingstoke: Palgrave Macmillan, 2011.

Guarnieri, Romana. »Lo Specchio delle anime semplici e Margherita Poirette«. Osservatore Romano (1946): 3. Ponatis v »Il Movimento del Libero Spirito: Testi e documenti«. Archivio italiano per la storia della pietà 4 (1965): 661-663.

Hamburger, Jeffrey F., in Susan Marti, ur. Crown and Veil: Female Monasticism from the Fifth to the Fifteenth Centuries. New York: Columbia University Press, 2008.

Jantzen, Grace. Power, Gender and Christian Mysticism. Cambridge: Cambridge University Press, 1996.

Juilfs, Jonathan H. »Mirrors on the Wall«. V: A Companion to Marguerite Porete and The Mirror of Simple Souls, 323-337. Boston: Brill, 2017.

Kangas, David. »Dangerous Joy: Marguerite Porete's Good-bye to the Virtues«. Journal of Religion 91.3 (2011): 299-319.

Kocher, Zan. »Literary Sources of the Mirror of Simple Souls«. V: A Companion to Marguerite Porete and The Mirror of Simple Souls, 96-119. Boston: Brill, 2017.

Kocijančič Nike, prev. in uvod. Knjiga Margery Kempe. Ljubljana: KUD Logos, 2006.

Kruger, Steven F. The Spectral Jew: Conversion and Embodiment in Medieval Europe. Minneapolis: University of Minnesota Press, 2006.

Lochrie, Karma. Margery Kempe and Translations of the Flesh. Philadelphia: University of Pennsylvania Press, 1991.

Mbembe, Achille. Necropolitics. Durham, nc: Duke University Press, 2019.

MacGregor, Kirk. »1 Corinthians 14:33b-38 as a Pauline Quotation-Refutation Device«. Priscilla Papers 32 (2018), 23-28.

Mizruchi, Ephraim H. Regulating Society: Beguines, Bohemians, and Other Marginals. Chicago: The University of Chicago Press, 1987.

Newman, Barbara. "Annihilation and Authorship: Three Women Mystics of the 1290s«. Speculum 91/3, (2016): 591-630.

Petroff, Elizabeth. Body and Soul: Essays on Medieval Women, and Mysticism. Oxford: Oxford University Press, 1994. 
Power, Eileen. Medieval English Nunneries c. 1275-1535. Cambridge: Cambridge University Press, 1922.

Podlesnik, Tamara. »Med neizrekljivostjo in telesom: Srednjeveška mističarka v luči psihoanalize, feminizma in literature». Doktorska disertacija, Univerza v Ljubljani, 2020.

Robinson, Joanne Maguire. Nobility and Annihilation in Marguerite Porete's Mirror of Simple Souls. suny Series in Western Esoteric Traditions. Albany: State University of New York Press, 2001.

Roest, Bert. "Female Preaching in the Late Medieval Franciscan Tradition«. Franciscan Studies 62 (2004): 119-154.

Röckelein, Hedwig. »Founders, Donors, and Saints: Patrons of Nuns' Convents«. V: Crown and Veil: Female Monasticism from the Fifth to the Fifteenth Centuries, 207-224. New York: Columbia University Press, 2008.

Rösener, Werner. "Household and Prayer: Medieval Convents as Economic Entities«. V: Crown and Veil: Female Monasticism from the Fifth to the Fifteenth Centuries, 245-258. New York: Columbia University Press, 2008.

Rubin, Miri. »Choosing Death? Experiences of Martyrdom in Late Medieval Europe«. V: Martyrs and Martyrologies: Papers Read at the 1992 Summer Meeting and the 1993 Winter Meeting of the Ecclesiastical History Society, ur. Diana Wood, 153-183. Oxford: Blackwell, 1993.

Scarborough, „Critical Approaches to Marguerite Porete«. V: A Companion to Marguerite Porete and The Mirror of Simple Souls, 295-322. Boston: Brill, 2017.

Staley Johnson, Lynn. »The Trope of the Scribe and the Question of Literary Authority in the Works of Julian of Norwich and Margery Kempe«. Speculum 66/4 (1991): 820-838.

Terry, Wendy R., in Robert Stauffer, ur. A Companion to Marguerite Porete and The Mirror of Simple Souls. Boston: Brill, 2017.

Vaneigem, Raoul. The Movement of the Free Spirit. New York: Zone Books, 1994.

Verdeyen, Paul. »Le procès de l'Inquisition contre Marguerite Porete et Guiard de Cressonessart (1309-10)«. Revue d'histoire ecclésiastique 81 (1986): 47-94.

Watson, Nicholas, in Jacqueline Jenkins, ur. The Writings of Julian of Norwich. University Park, PA: Penn State Press, 2006.

Wilson, Katharina, ur. in uvod. Medieval Women Writers. Athens: University of Georgia Press, 1984. 


\section{IZVLEČEK}

Prispevek obravnava Margareto Porete in Ogledalo preprostih duš skozi prizmo Foucaultovih predavanj o "veridikciji« oziroma štirih prevladujočih načinih izrekanja resnice: prerokbi, modrosti, poučevanju in pareziji. Tudi v svojih hibridnih oblikah so bili ti načini še vedno vezani na posebne institucije izrekanja resnice, s specifičnimi udeleženci, področji nagovarjanja in načini izrekanja. Besedilo v tem okviru analizira Margaretin proces in osrednje ideje njenega dela ter prepozna mistično misel Margarete Porete kot poskus oblikovanja novega prostora $\mathrm{v}$ obstoječih režimih izrekanja resnice; pri tem je njeno orodje medij knjige oziroma strateško preoblikovanje odnosa med telesom in pisanjem.

KLJUČNe BESEDE: Margareta Porete, Ogledalo preprostih duš, Michel Foucault, mistika, izrekanje resnice 
VERIDICTION IN THE MIRROR OF SIMPLE SOULS BY MARGUERITE PORETE

\begin{abstract}
The article looks at Marguerite Porete and her Mirror of Simple Souls through the lens of Michel Foucault's ideas of veridiction, and its four distinctive types: prophecy, wisdom, teaching, and parrhesia. Even in their hybrid forms, these modes were still tied to specific institutions of truth-telling, with particular participants, spheres of address, and manners of speaking. The article looks at Marguerite's trial and the central tenets of her work within this framework, and recognizes her mysticism as an attempt to carve out a new space within existing regimes of truth-telling; she does so by relying on the medium of the book or, specifically, a strategic interrelation of body and writing.
\end{abstract}

KEYWORDS: Marguerite Porete, Mirror of Simple Souls, Michel Foucault, mysticism, veridiction 